\title{
Critical appraisal of lurasidone in the management of schizophrenia
}

This article was published in the following Dove Press journal:

Neuropsychiatric Disease and Treatment

12 April 2012

Number of times this article has been viewed

\section{Silvio Caccia \\ Luca Pasina \\ Alessandro Nobili \\ Istituto di Ricerche Farmacologiche, "Mario Negri”, Milan, Italy}

Correspondence: Luca Pasina Laboratory of Quality Assessment of Geriatric Therapies and Services, "Mario Negri" Institute for Pharmacological Research, via Giuseppe La Masa, 19, 20I56, Milan, Italy Tel +39239014579

Fax +39239001916

Email luca.pasina@marionegri.it
Abstract: Lurasidone is a new atypical antipsychotic in the benzoisothiazoles class of chemicals. Like most second-generation antipsychotics it is a full antagonist at dopamine $\mathrm{D}_{2}$ and serotonin $5-\mathrm{HT}_{2 \mathrm{~A}}$ receptors, and is a partial agonist at $5-\mathrm{HT}_{1 \mathrm{~A}}$ receptors, a property shared by some but not all older agents. It has much greater affinity for 5- $\mathrm{HT}_{7}$ subtype receptors than other atypical antipsychotics. Pharmacokinetic studies showed that lurasidone is reasonably rapidly absorbed, with bioavailability appearing to be increased by food. Lurasidone undergoes extensive metabolism to a number of metabolites, some of which retain pharmacological activities. Metabolism is mainly by CYP3A4, resulting in steady-state concentrations that vary between individuals and are potentially affected by strong inducers and inhibitors of this enzyme. Short-term clinical trials have demonstrated the efficacy of lurasidone in acute schizophrenia, with doses of 40 and $80 \mathrm{mg}$ /day giving significant improvements from baseline in the PANSS and BPRS scores. The most common adverse events are nausea, vomiting, akathisia, dizziness, and sedation, with minimal increases in the risk of developing metabolic syndrome. Lurasidone did not raise the risk of QTc interval prolongation, although additional studies are required. Long-term trials are also needed to assess the risk of new-onset diabetes. Ongoing trials in patients with bipolar disorder are being completed but, again, efficacy and safety have been investigated only in a few short-term clinical trials.

Keywords: lurasidone, pharmacology, pharmacokinetics, efficacy, safety

\section{Introduction}

Schizophrenia is one of the most debilitating psychiatric disorders and affects about $1 \%$ of the population worldwide. ${ }^{1}$ It causes recurring and progressive episodes of positive symptoms (eg, hallucination, delusions), negative symptoms (eg, alogia, anhedonia), disturbed cognitive function (eg, impaired attention), and aggressive/ hostile and depressive/anxious abnormalities. ${ }^{2,3}$ It is associated with an increased risk of mortality and imposes a huge financial burden on society. ${ }^{4,5}$ Optimal treatment could lighten this burden, ${ }^{6}$ but it is challenging to develop antipsychotic drugs that stabilize the patient and reduce the symptoms and likelihood of relapse.

Until recently, pharmacological treatment of schizophrenia was based on conventional agents such as chlorpromazine and haloperidol (generally called firstgeneration antipsychotics) whose action is thought to be the result of their high-affinity dopamine $\mathrm{D}_{2}$ receptor antagonism. ${ }^{7}$ Although efficacious against positive symptoms, these agents have limited efficacy against negative symptoms and can induce various severe adverse effects including extrapyramidal symptoms (EPS), which also probably reflect blockage of $\mathrm{D}_{2}$ receptors. Nowadays, however, these drugs have been replaced 
by second-generation antipsychotics (also called atypical agents, whose prototype is clozapine), due to a more acceptable tolerability profile. ${ }^{8,9}$ While each drug of this atypical class has its own receptor profile, most of them show higher affinity for serotonin type $2 \mathrm{~A}\left(5-\mathrm{HT}_{2 \mathrm{~A}}\right)$ than $\mathrm{D}_{2}$ receptors, which have been linked to their better effects on the negative symptoms of schizophrenia. ${ }^{10,11}$ Also, they all share the propensity to cause minimal EPS at doses that are clinically active against positive symptoms. ${ }^{12-14}$

Nevertheless, $\mathrm{D}_{2}$-related treatment-stopping side effects such as weight gain, lipid dysregulation, and hyperglycemia can still arise with some of these antipsychotics, ${ }^{15-17}$ and they may be associated with cardiovascular adverse events, particularly prolongation of cardiac action potential QT intervals, an effect which may cause cardiac arrhythmias. ${ }^{18}$ Recent pragmatic or effectiveness clinical trials such as the clinical antipsychotic trials of intervention effectiveness (CATIE) and cost utility of the latest antipsychotic drug in schizophrenia study (CUtLASS) have challenged the view of the advantages of second-generation antipsychotics over conventional agents, ${ }^{19-21}$ although this conclusion is debated. ${ }^{22,23}$ Efforts are continuing to identify new molecules with a balance of effects on dopamine and 5-HT receptors, as these would result in a better therapeutic profile. This has led to some new antipsychotic options, ${ }^{24,25}$ including the benzisothiazole derivative lurasidone, which at the time of writing is the most recently introduced chemical. ${ }^{26}$

Recent reviews have described the in vitro and in vivo neuropharmacology of lurasidone, and have summarized the trials examining its therapeutic efficacy and tolerability in the management of schizophrenia and schizoaffective disorder. ${ }^{27-29}$ Others have discussed its pharmacokinetic and metabolic profiles and compared these to other recently released antipsychotics. ${ }^{30}$ This review further examines the clinical pharmacology, pharmacokinetics, efficacy, and safety of this antipsychotic.

\section{Methods}

This review is based on a literature search on the international database PubMed. The keywords used were "lurasidone" and "schizophrenia"; no date constraints were utilized. Data were also collected from the product labeling available at the manufacturer's website (www.ds-pharma.com). A query "lurasidone" on the ClinicalTrials.gov website (www.clinicaltrials.gov) and the FDA's website (www.fda. gov) did not result in the identification any additional completed clinical studies. Twenty-nine records that matched the two keywords were originally identified from PubMed, with three of these being clinical trials (one phase II trial and two phase III trials).

\section{Pharmacological profile}

Chemically, lurasidone or $(3 \mathrm{a} R, 4 S, 7 R, 7 \mathrm{a} S)-2-\{(1 R, 2 R)-2-[4-$ (1,2-benzisothiazol-3-yl)piperazin-1-ylmethyl] cyclohexylmethyl hexahydro-4,7-methano- $2 H$-isoindole-1,3-dione hydrochloride is structurally related to perospirone and ziprasidone (see Figure 1 for chemical structures), and older benzisothiazoles with antipsychotic activity. In a similar chemical class are the benzisoxazole derivatives risperidone, its active metabolite paliperidone, and iloperidone. Besides the chemical structure, benzisothiazoles and benzisoxazoles shares some minor metabolic pathways. ${ }^{31}$

As with its structurally related drugs and many other atypical antipsychotics, lurasidone has high affinity for the dopamine $\mathrm{D}_{2}$ and $5-\mathrm{HT}_{2 \mathrm{~A}}$ receptors. However, it has the highest affinity of any atypical antipsychotic for the 5- $\mathrm{HT}_{7}$ receptor, the blockade of which may also contribute to its antipsychotic effects. ${ }^{32}$ Experimental studies support the positive effects of $5-\mathrm{HT}_{7}$ antagonists on cognitive impairment, ${ }^{33,34}$ memory, ${ }^{35}$ and mood symptoms. ${ }^{36}$

Lurasidone also has high affinity for the $5-\mathrm{HT}_{1 \mathrm{~A}}$ subtype, with which it interacts as a partial agonist in a similar way to some but not all antipsychotics (eg, the benzisothiazoles perospirone and ziprasidone, but not the benzisoxazoles risperidone and iloperidone). ${ }^{32} 5-\mathrm{HT}_{1 \mathrm{~A}}$ receptors, widely expressed in the central nervous system and upregulated in the frontal cortex, have been implicated in the enhancement of cognitive function in pharmacological models ${ }^{37}$ and patients with schizophrenia; the stimulation of these receptors could normalize frontal cortex function and reduce side effects induced by dopamine $\mathrm{D}_{2}$ receptor blockade such as EPS, including dystonia and diskinesia, abolishing catalepsy and the blockade of pituitary-located $\mathrm{D}_{2}$ receptors that control the prolactine release that has been observed experimentally and clinically with older atypical antipsychotics. ${ }^{37-39}$ The so-called "third-generation" antipsychotic aripiprazole is also a 5- $\mathrm{HT}_{1 \mathrm{~A}}$ receptor partial antagonist but, unlike benzisothiazole derivatives, it combines this activity with $\mathrm{D}_{2}$ partial antagonism and also exhibits high-affinity $\mathrm{D}_{3}$ antagonism. ${ }^{40}$

Lurasidone has affinity for $\alpha_{2 c}$-adrenergic receptors, which are also implicated in the enhancement of cognitive function, and low affinity for $\alpha_{1}$-adrenergic receptors, which suggests that it will have a low propensity for causing orthostatic hypotension. It has minimal affinity for $5-\mathrm{HT}_{2 \mathrm{C}}$ receptors, so would not be expected to cause weight gain. It has negligible affinity for histamine $\mathrm{H}_{1}$ and muscarinic 


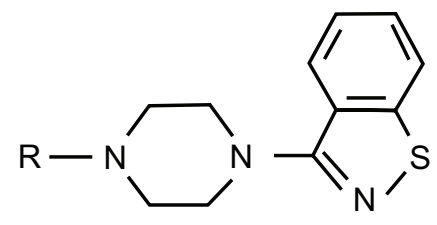

R Drug
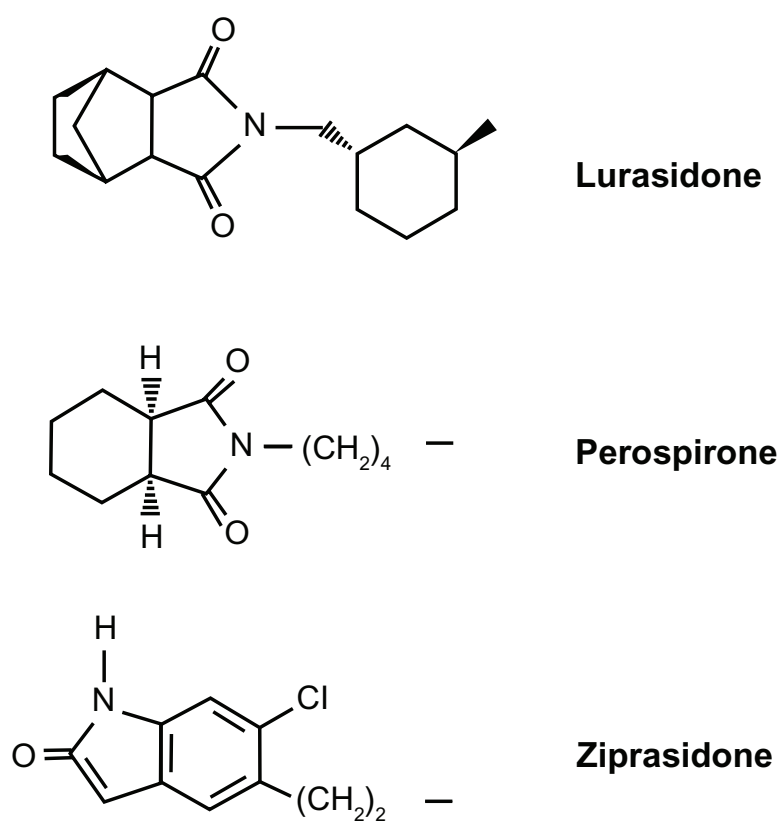

Figure I Chemical structures of lurasidone, ziprasidone, and perospirone. R $=\mathrm{H}$ is I-(I,2-benzisothiazol-3-yl)-piperazine (BITP).

receptors, which are linked to sedation and weight gain, and have negative cognitive effects. ${ }^{32}$

In vivo lurasidone and some of its metabolites were similar to other antipsychotics in their efficacy in animal models predictive of antipsychotic activity. ${ }^{32}$ Improved cognitive effects and mood stabilization were also observed in various learning and memory impairment models in rats. Evaluation of the secondary pharmacodynamic properties of lurasidone showed only very weak potential for drug-associated EPS and central nervous system (CNS) depressive effects such as exaggeration of anesthesia, muscle relaxation, and inhibition of motor coordination. Findings are summarized in Table 1.27,32,41

\section{Pharmacokinetics}

Lurasidone is rapidly absorbed, reaching peak concentrations within 1.5-3 hours $\left(\mathrm{t}_{\max }\right)$ after single and multiple oral doses.
Its pharmacokinetics were linear in the range of 20 to $160 \mathrm{mg}$ in healthy and schizophrenic subjects, but intersubject variability was high in both populations $(30 \%-50 \%$ in healthy subjects, $30 \%-60 \%$ in patients with schizophrenia) in terms of plasma maximum concentrations $\left(\mathrm{C}_{\max }\right)$ and area under the curve (AUC) over the dosing interval $\left(\mathrm{AUC}_{\tau}\right) .{ }^{41}$ Based on the amount of lurasidone that was excreted unchanged in urine in fasting healthy subjects, systemic bioavailability was between $9 \%$ and $19 \%$. However, absorption increased when the drug was taken with food; in a study comparing the steady-state pharmacokinetics of lurasidone $120 \mathrm{mg}$ with meals of various calorie and fat content versus the fasted state, lurasidone exposure as measured by $\mathrm{AUC}$ and $\mathrm{C}_{\max }$ increased two- to three-fold in the presence of food, although there was no significant difference in exposure based on the calorie/fat content of the meal. These findings have been reviewed elsewhere..$^{28,29,42}$ 
Table I Main pharmacological properties of lurasidone

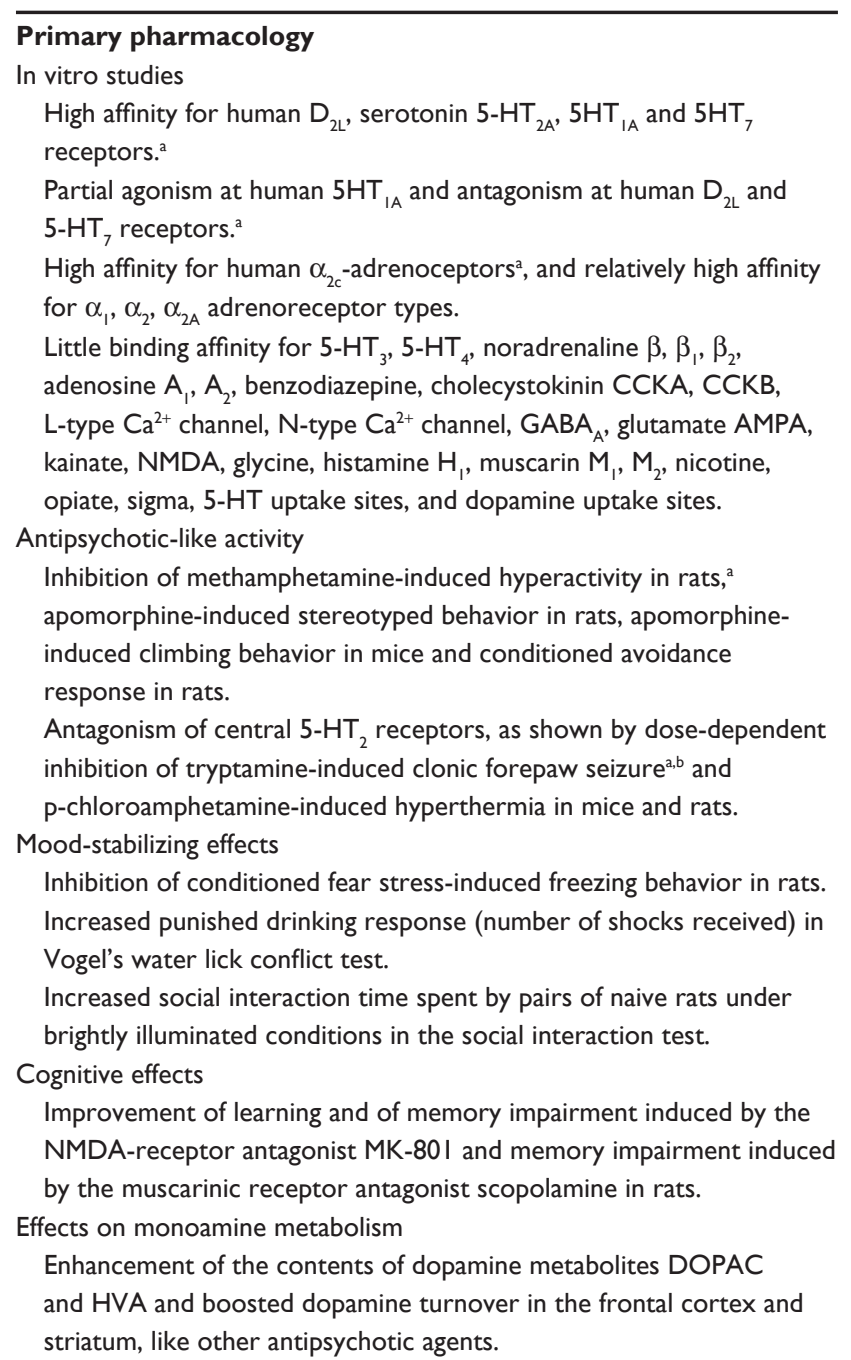

\section{Secondary pharmacology}

Potential extrapyramidal symptom liability

No cataleptogenic activity in either mice or rats, whereas comparator antipsychotics dose-dependently induced catalepsy.

No significant effects on the pole-descending time and forepaw reaction time in animal models, unlike comparator antipsychotics.

Potential for CNS depression

Weaker effects than comparator antipsychotics on spontaneous locomotor activity, hexobarbital-induced anesthesia, muscle relaxation and motor coordination and MES-induced seizures in animal models.

Notes: ${ }^{2}$ These properties are shared by metabolites ID-I4283 and ID-14326, and bmetabolite ID-1 |6I 4 or I-(1,2-benzisothiazol-3-yl)-piperazine.

Abbreviations: DOPAC, 3, 4-dihydroxyphenylacetic acid; HVA, homovanillic acid; MES, maximal electric shock; NMDA, N-methyl-D-aspartate.

Adapted from references $27,32,41$.

Once absorbed, lurasidone is similar to most lipophilic antipsychotics in that it extensively distributes in tissues. It rapidly enters the CNS, with a dose-dependent increase in $\mathrm{D}_{2}$ receptor occupancy up to $60 \mathrm{mg}(77.4 \%-84.3 \%$, depending on the region) with no further increases after $80 \mathrm{mg}$, at about the $t_{\text {max }}$ of plasma concentrations in healthy subjects. ${ }^{27}$
The mean apparent volume of distribution greatly exceeded the body water volume, averaging $6173 \mathrm{~L}$ at the recommended starting dose of $40 \mathrm{mg}$. Lurasidone has high binding to human plasma albumin and alpha-1-glycoprotein ( $\geq 99 \%)$. The mean fraction of lurasidone distributed in red blood cells was approximately $12 \%$ in vivo in healthy subjects.

In animal studies, lurasidone penetrated the placental barrier and distributed into the fetus, and was excreted in milk during lactation. The manufacturer's prescribing information should therefore be consulted for administration guidelines for pregnant and nursing women. ${ }^{42}$

Elimination is essentially by metabolism, primarily involving CYP3A4-mediated oxidative N-dealkylation, hydroxylation of the norbornane ring or cyclohexane ring, S-oxidation of the isothiazolyl ring, reductive cleavage of the isothiazole ring followed by S-methylation, and combinations of two or more of these pathways. The two main metabolites, the acidic derivative ID-20219 and its hydroxylated derivative ID-20220, had negligible affinity for the rat $\mathrm{D}_{2}$ receptor and the human $\mathrm{D}_{2 \mathrm{~L}}$ receptor, or for the rat 5- $\mathrm{HT}_{2}$ and human $5-\mathrm{HT}_{1 \mathrm{~A}}, 5-\mathrm{HT}_{2 \mathrm{~A}}$, and $5-\mathrm{HT}_{7}$ receptors.

Besides ID-20219, lurasidone N-dealkylation yields to 1-(1,2-benzisothiazol-3-yl)-piperazine (ID-11614 or BITP), a metabolite common to perospirone and ziprasidone (Figure 1). This metabolite also had poor in vitro activity at the $\mathrm{D}_{2}$ and $5-\mathrm{HT}_{2}$ receptors and no antipsychotic-like action in preclinical tests although it concentrated in rat brain, raising the acetylcholine content (see reference 31 for review). BITP shares some of the in vivo pharmacodynamic properties of lurasidone in rodent and non-rodent species. ${ }^{26}$ After oral doses of radiolabeled lurasidone, exposure to ID-11614 varied depending on the species and dose, ranging from approximately $12 \%$ in rats and dogs at $50 \mathrm{mg} / \mathrm{kg}$ to $100 \%$ in monkeys at $10 \mathrm{mg} / \mathrm{kg}$ of the plasma exposure to lurasidone, but there is little and only incomplete information on its pharmacokinetics compared with the parent drug in humans. ${ }^{26}$

Two other metabolites, the exo-hydroxy derivative ID-14283 and the endo-hydroxy derivative ID-14326 (see Figure 2 for chemical structures), showed affinity for $\mathrm{D}_{2}$ and $5-\mathrm{HT}_{2 \mathrm{~A}}$ comparable to lurasidone. Both also had high affinity for human receptor subtypes $5-\mathrm{HT}_{1 \mathrm{~A}}$ and $5-\mathrm{HT}_{7}$, similar to lurasidone's affinity for these subtypes. In vitro functional activity studies suggested that both ID-14283 and ID-14326 were partial agonists of the human 5-HT $1 \mathrm{~A}$ receptor and potent antagonists of human $\mathrm{D} 2 \mathrm{~L}$ and $5-\mathrm{HT}_{7}$ receptors, further suggesting that hydroxylation at position 5 or 6 of lurasidone's norbornane skeleton had little influence on its 


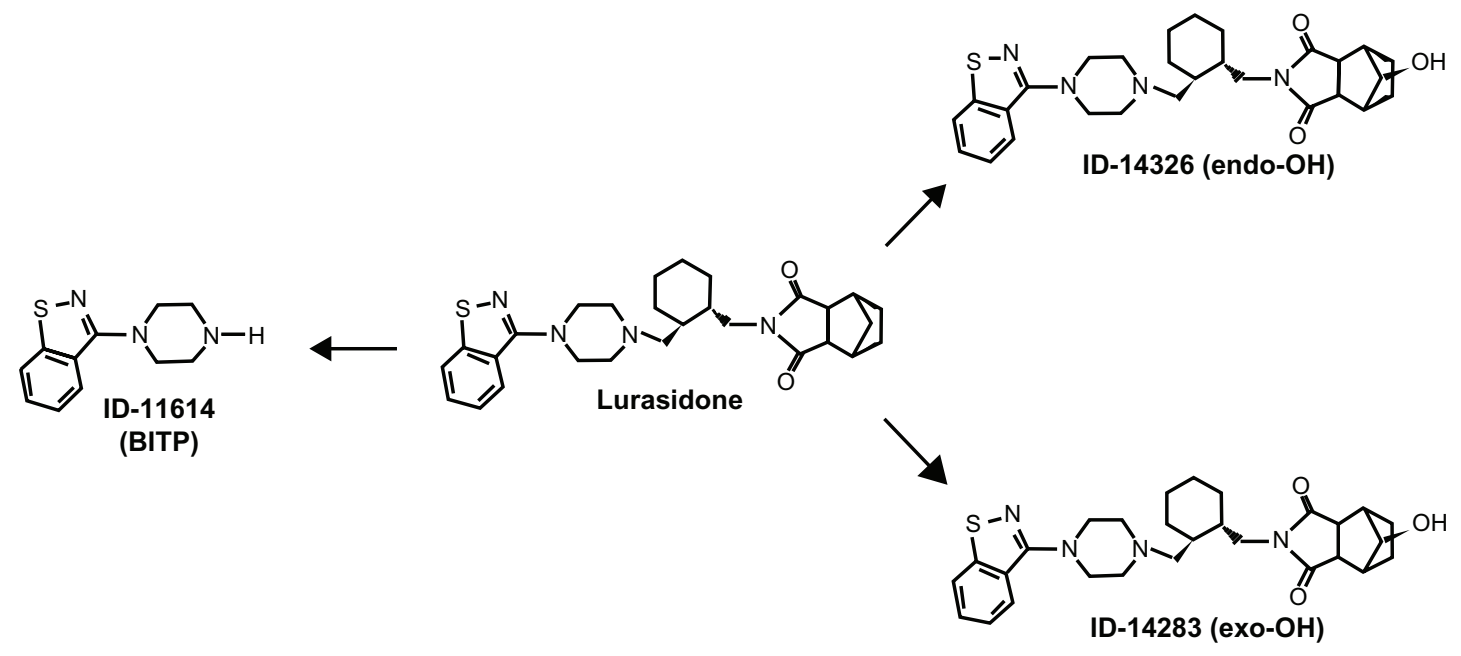

Figure 2 The active metabolites of lurasidone. BITP = I-(I,2-benzisothiazol-3-yl)-piperazine.

neuropharmacological action. ${ }^{42}$ After oral doses of 20 to $80 \mathrm{mg} /$ day of lurasidone hydrochloride in Japanese male and female patients with schizophrenia, the mean exposure $\left(\mathrm{C}_{\max }\right.$ and $\mathrm{AUC}_{24}$ ) to ID-14283 and ID-14326 was approximately $24 \%$ and $3 \%$, respectively, of that to lurasidone - this indicates that these metabolites, particularly ID-14283, contribute to the antipsychotic action of lurasidone. As with the parent compound, the two metabolites showed similar differences in exposure under fed as opposed to fasting conditions. ${ }^{28}$ Both are slightly less bound to human plasma proteins than the parent drug $(98.8 \%) ;{ }^{42}$ however, brain uptake and concentrations compared to lurasidone have not yet been reported.

In excretion studies in healthy subjects, after a single dose of radiolabeled lurasidone was administered approximately $80 \%$ of total radioactivity was recovered in feces and $9 \%$ in urine. ${ }^{42}$ In single-dose pharmacokinetic studies in healthy subjects (doses $<100 \mathrm{mg} /$ day), the mean terminal half-life ranged from 12.2 to 18.3 hours in some studies, but at steady state in patients with schizophrenia it rose to between 28.8 and 37.4 hours. ${ }^{27}$ Thus, after repeated oral doses in schizophrenic patients, steady-state concentrations of lurasidone were achieved within 7 days. ${ }^{42}$

\section{Special populations}

Healthy elderly men had approximately $31 \%$ lower lurasidone $\mathrm{C}_{\max }$ than younger males, but their AUCs were similar. ${ }^{27}$ Exposure to lurasidone and its active metabolites in elderly patients with psychosis and in younger subjects was similar after $20 \mathrm{mg}$ /day lurasidone hydrochloride. Therefore, as with most second-generation antipsychotics, no dose adjustment is needed in elderly people. ${ }^{42}$ Exposure in women was $18 \%$ higher than in men, which indicates that oral clearance was lower in women, as assessed by population pharmacokinetic analysis. Asians had $40 \%$ less clearance than Caucasians, but these differences in exposure are also not expected to be clinically relevant. ${ }^{41,42}$ Lurasidone pharmacokinetics have not been examined in pediatric and adolescent patients.

Renal impairment led to increased mean exposure to lurasidone after oral doses of $40 \mathrm{mg}$ lurasidone hydrochloride. Compared with healthy matched controls, mild, moderate, and severe renal disease led to mean $\mathrm{C}_{\max }$ increases of $40 \%$, $92 \%$, and $54 \%$, and $\mathrm{AUC}$ increases of $53 \%, 91 \%$, and $100 \%$, respectively. The mean $t_{1 / 2}$ was also prolonged with increasing severity of renal impairment. ${ }^{41}$ The manufacturer recommends that doses should not exceed $40 \mathrm{mg}$ in moderate and severe renal-impaired patients. This same dose should also not be exceeded in patients with moderate or severe hepatic disease..$^{42} \mathrm{In}$ a single-dose study with $20 \mathrm{mg}$ lurasidone hydrochloride, mean $\mathrm{AUC}_{\text {(0-last) }}$ was 1.5 times greater in subjects with mild hepatic impairment, 1.7 times greater in subjects with moderate impairment, and 3 times greater in those with severe impairment, compared to healthy matched subjects. Mean $\mathrm{C}_{\max }$ was $1.3,1.2$, and 1.3 times higher for mild, moderate, and severely impaired patients, respectively, when compared to healthy matched subjects. The mean $t_{1 / 2}$ for patients with moderate hepatic impairment was greater than in healthy subjects (112 versus 93 hours, but in healthy subjects this value is much higher than in previous studies); there are no data for severe hepatic impairment. Increased exposure to active metabolites and their elimination $t_{1 / 2}$ were also observed with increasing severity of hepatic impairment compared with the healthy matched control group, although results were not detailed. ${ }^{41}$ 


\section{Drug interactions}

The manufacturer recommends caution when lurasidone is co-administered with CYP3A4 inducers or inhibitors; ketoconazole (400 mg daily), for example, increased exposure to lurasidone by 7-9 times in healthy subjects taking $10 \mathrm{mg}$, while diltiazepam ( $240 \mathrm{mg}$ /day), a moderate CYP3A4 inhibitor, doubled the AUC and $\mathrm{C}_{\max }$ of the parent drug and its active metabolite ID-14283 in healthy subjects. The CYP3A4 inducer rifampin (600 mg/day) reduced exposure to lurasidone by as much as $85 \%$ in a single-dose study (40 mg) in healthy subjects. ${ }^{42}$

Lurasidone itself is a moderate inhibitor of CYP3A4 in human tissue preparations and in vivo at steady state $\left(120 \mathrm{mg} /\right.$ day) it increased the $\mathrm{C}_{\max }$ and $\mathrm{AUC}_{(0-24)}$ of midazolam $(5 \mathrm{mg}$ ) by approximately $21 \%$ and $44 \%$, respectively, although these changes are considered clinically irrelevant. Similarly, oral contraceptives containing ethinyl estradiol and norelgestromin resulted in negligible changes in $\mathrm{C}_{\max }$ and AUC when coadministered with lurasidone ( $40 \mathrm{mg} /$ day). In vitro studies using human tissue preparations suggested that clinically relevant concentrations of lurasidone also moderately inhibited CYP2C8-, CYP2C9-, CYP2C19-, and CYP2B6-mediated reactions. ${ }^{41,42}$

Lurasidone has not been shown to affect protein binding of biperiden, flunitrazepam, haloperidol, or diazepam, the few drugs that have been studied in vitro. Similarly, it did not affect protein binding of concomitant highly-bound drugs with affinity for albumin and alpha-1-glycoprotein. ${ }^{41}$

Although lurasidone is not a substrate of the P-glycoprotein (P-gp; and nor is its active metabolite ID-14283), it had an inhibitory effect on digoxin transport in vitro in cells expressing human P-gp. ${ }^{27}$ However, co-administration at steady state $(120 \mathrm{mg} /$ day $)$ with a single dose of digoxin $\left(0.25 \mathrm{mg}\right.$ ) increased the $\mathrm{C}_{\max }$ and $\mathrm{AUC}_{24}$ of digoxin by only about $10 \% .^{42}$

No interaction was observed when lurasidone (120 mg) was administered with lithium (600 $\mathrm{mg}$ twice daily) to patients with schizophrenia, schizophreniform, or schizoaffective disorder.

\section{Efficacy in clinical studies}

Table 2 summarizes the nine clinical studies investigating the efficacy of lurasidone for schizophrenia in adults (mean age 39 years, range 18 to 72 years). ${ }^{28,29,41,43-47}$ Seven of these studies were short-term (6-week) randomized, double-blind placebo-controlled studies, with three of these seven being phase II trials and four being phase III trials. The FDA used five studies for drug approval. ${ }^{41}$ An active comparator (haloperidol, quetiapine, or olanzapine) was used in four trials. ${ }^{41,45}$ Data on efficacy was also available from a 3-week study that compared lurasidone with ziprasidone in stable patients with schizophrenia or schizoaffective disorders, ${ }^{43}$ and from an 8-week dose-response trial in inpatients and outpatients with schizophrenia. ${ }^{48}$

A dose-response study of lurasidone in which 20,40 , or $80 \mathrm{mg} /$ day was administered indicated that 40 and $80 \mathrm{mg} /$ day were associated with significant improvements from baseline in the positive and negative syndrome scale (PANSS) and brief psychiatric rating scale (BPRS) scores, and achieved significantly better results than $20 \mathrm{mg} /$ day ${ }^{48}$ Some studies used changes in clinical global impression severity (CGI-S) score, clinical global impression improvement (CGI-I) score, and PANSS subscale score as secondary endpoints. At 6 weeks, efficacy primary and secondary measures were consistently in favor of lurasidone $80 \mathrm{mg}$ /day over placebo (except in one failed trial). Two studies also showed efficacy for doses of 40 and $120 \mathrm{mg}$ /day (see Table 2). ${ }^{41,43-45}$

A pooled analysis based on a five-factor model of schizophrenia from four short-term, double-blind, placebocontrolled studies demonstrated that at 6 weeks, lurasidone was significantly better than a placebo in improving all five PANSS factors (positive, negative, disorganized thought, hostility, and depression/anxiety scores) ${ }^{49}$ Time of onset (in the first 3 to 7 days) and trajectory of improvement was similar across the $40-120 \mathrm{mg} /$ day dose range when PANSS scores were considered. No differences suggestive of a dose-response relationship were found in GCI-S for $40-120 \mathrm{mg} /$ day. Early onset, by day 7, was reported in the changes in CGI-S scores for $80-120 \mathrm{mg}$ /day. This pooled analysis found no clear dose-response relationship, and generalizability was limited by the characteristics of patients enrolled in the studies: there were high percentages of patients who were white $(32 \%-52 \%)$, male $(69 \%-79 \%)$, and aged between 37 and 41 years.

In a 3-week study directly comparing lurasidone $120 \mathrm{mg} /$ day and ziprasidone $160 \mathrm{mg}$ /day in stable outpatients with schizophrenia, efficacy was similar, with an earlier onset of improvement in PANSS total score by day $7 .^{43,47}$ This study also evaluated the cognitive effect of lurasidone and found no between-group differences on a performance-based cognitive functioning assessment battery. Unlike ziprasidone, however, lurasidone showed significant within-group improvement from baseline on the matrices consensus cognitive battery (MCBB) composite score and on the schizophrenia cognition rating scale (SCoRS). Another trial was considered failed because neither lurasidone (20,40, or $80 \mathrm{mg}$ /day) nor 


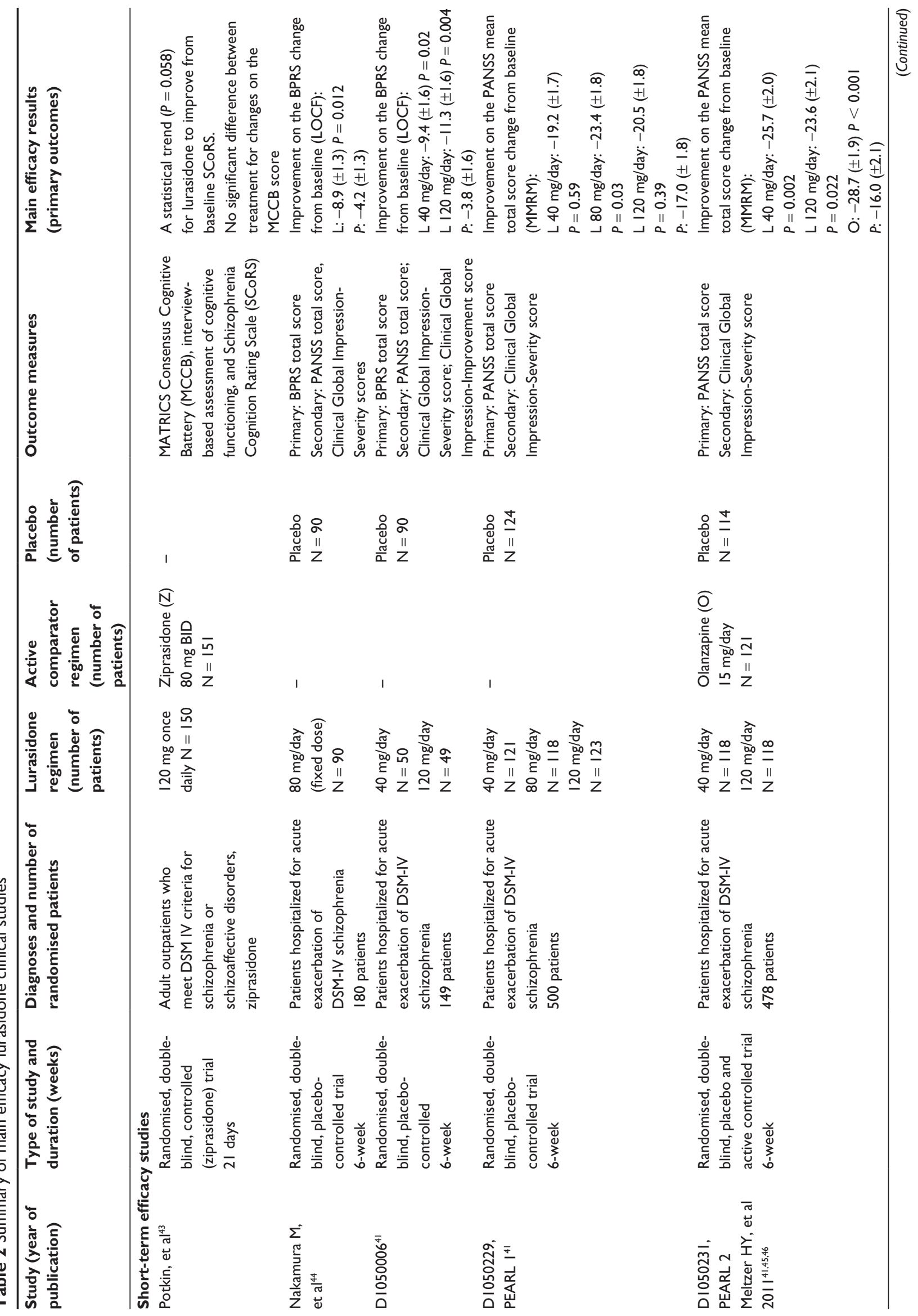




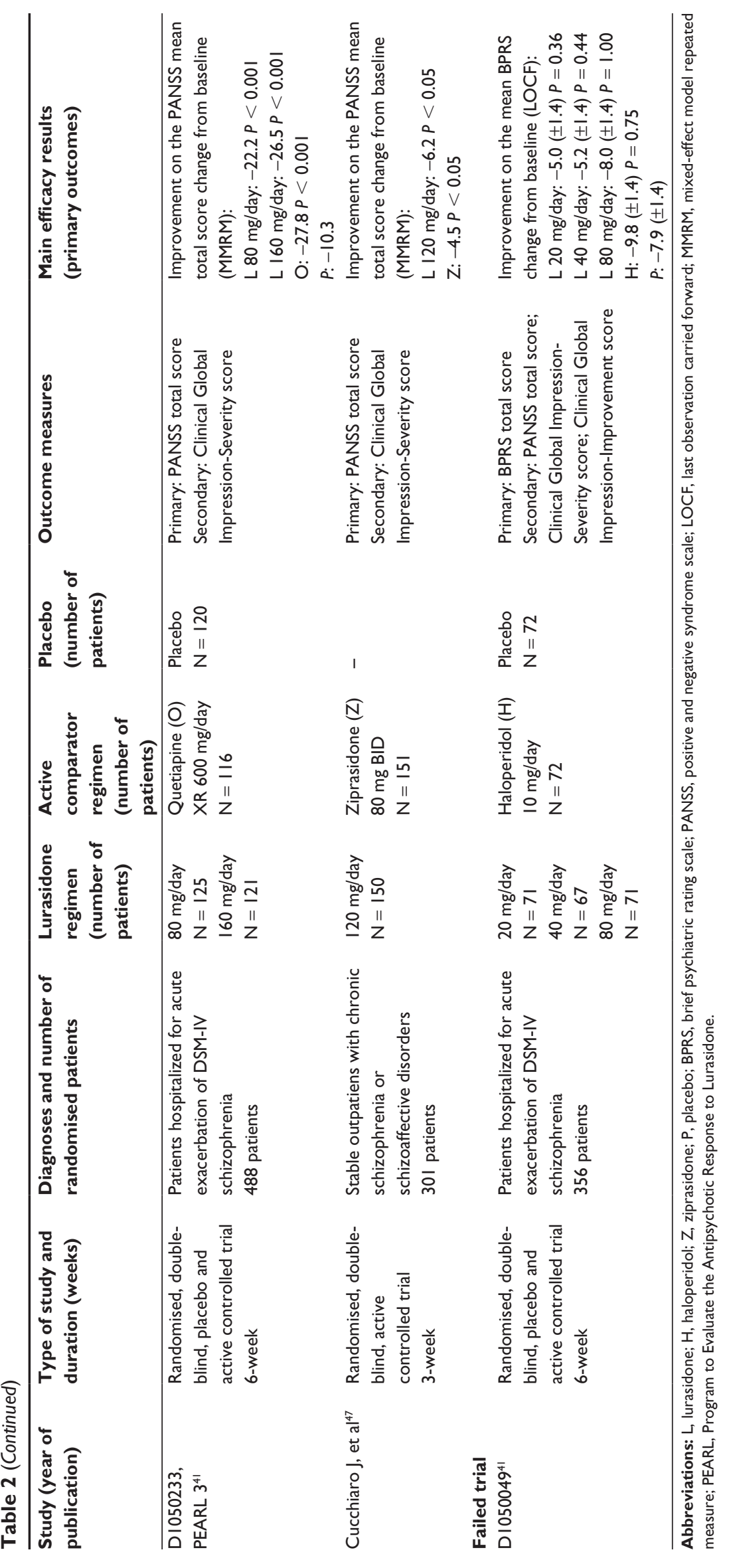


haloperidol (10 mg/day) differed from placebo in their effects on the psychopathological outcome measures. ${ }^{41}$

The long-term efficacy of lurasidone in schizophrenia has been evaluated in the extension phase of some short-term studies, but results have not been published. Data on the maintenance of clinical effect of lurasidone in schizophrenia patients treated for up to 8 months in the program to evaluate the antipsychotic response to lurasidone (PEARL) 2 extension trial were encouraging. ${ }^{29,50}$

No consistent data are available for assessing the efficacy of lurasidone in depressive symptoms associated with schizophrenia. The only significant improvement in patient depression that has been reported following lurasidone treatment was a secondary analysis of a trial evaluating the efficacy of lurasidone in patients with schizophrenia who were experiencing depressive symptoms according to the Montgomery-Asberg depression rating scale. ${ }^{51}$

A recent review discussed the limitations of data on efficacy, particularly the lack of response rates for the active comparator, the different definitions for response from one study to another, the inclusion of patients quite different from those encountered in clinical practice, and the data sources (most clinical data are from abstracts or posters, and very few reports have been published in peer reviewed medical journals). ${ }^{29}$

\section{Safety and tolerability Common adverse events}

Preliminary information, mainly disclosed in study reports and posters, suggests that lurasidone is well tolerated, with a lower discontinuation rate than placebo. The drug's short-term safety profile has been evaluated in randomized double blind phase II and phase III trials of 3 to 6 weeks' duration, one of which included 1004 lurasidone-treated and 455 placebotreated patients. Active comparators were haloperidol, ziprasidone, risperidone, quetiapine, and olanzapine. ${ }^{29,52,53}$ Only three short term clinical trials have been published; the main adverse drug reactions are reported in Table 3. ${ }^{43-45}$ Safety data based on pooled analyses from five short-term, placebo-controlled studies covered 1004 lurasidone-treated patients and 455 placebo-treated patients. ${ }^{52,54}$ The most frequent adverse events (incidence $\geq 5 \%$ ) were akathisia (15\%), nausea (12\%), sedation (12\%), somnolence (11\%), Parkinsonism (11\%), insomnia (8\%), agitation (6\%), anxiety $(6 \%)$, and dystonia $(5 \%)$. Pooled analyses indicate that $8 \%$ of the lurasidone group and $4 \%$ of the placebo group discontinued treatment due to adverse events, with no dose-related differences in the 40-120 mg/day range. Apparent dose-related adverse reactions were akathisia and somnolence. Other common adverse events did not appear to be dose-related.

Long-term safety data are available only in manufacturer's communications. ${ }^{50}$ Compared to risperidone, lurasidone had a favorable safety profile at 12 months, with a significantly lower incidence of somnolence, constipation, and weight gain. Akathisia, nausea, and vomiting were more frequent with lurasidone, which is similar to the results of a short-term quetiapine and olanzapine trial. ${ }^{42,45,50}$

\section{Extrapyramidal symptoms and akathisia}

In the short-term clinical trials, EPS, akathisia, and dystonia were more frequent in lurasidone-treated patients $(14.7 \%$, $15 \%$, and $4.7 \%$, respectively) than in the placebo group $(5.1 \%$, $3.3 \%$, and $0.7 \%$, respectively). However, the mean changes from baseline were similar for EPS and dyskinesias, and very close to placebo for akathisia ( 0.2 for lurasidone and 0.0 for placebo). ${ }^{42,52-55}$ Lurasidone was not significantly associated with movement disorders, and EPS (including dystonia) was seen at the highest dose of lurasidone (120 mg/day).$^{53}$ However, patients treated with lurasidone required more anticholinergic medications (23\%) than those treated with olanzapine (18\%) and placebo (11\%), though less than haloperidol $(53 \%) .{ }^{55}$ Only akathisia appeared to be dose-related. In a longterm comparative trial with risperidone, akathisia occurred in $14.3 \%$ of lurasidone-treated patients ( $40-120 \mathrm{mg} /$ day) and $7.9 \%$ of risperidone-treated patients. ${ }^{50,53}$

\section{QT interval}

In the short-term lurasidone trials, there were no reports of increases in QTc $>500 \mathrm{msec}$ and no electrocardiographic abnormalities. ${ }^{44,53-55}$ When compared with ziprasidone over a 3-week period, no clinically significant elevations in QTc were reported, and lurasidone was associated with a smaller change in QTc than ziprasidone (+0.3 msec and +3.3 msec, respectively). ${ }^{43}$ Compared to olanzapine and placebo, mean changes in QTc were similar for lurasidone 40 and $120 \mathrm{mg} /$ day (+5.1 and $+4.5 \mathrm{msec}$, respectively), olanzapine $(+4.4 \mathrm{msec})$ and placebo $(+3.8 \mathrm{msec}){ }^{45}$ The percentage of women was very low in both studies (30\% for lurasidone and $29.1 \%$ for ziprasidone in the first study; ${ }^{43} 22 \%$ and $21 \%$ for lurasidone 40 and $120 \mathrm{mg} /$ day, $22 \%$ for olanzapine, and $23 \%$ for placebo in the second study), ${ }^{45}$ which may be significant as gender is a risk factor for QTc prolongation and torsades des pointes.

\section{Metabolic side effects}

No significant metabolic effects were reported for lurasidone. In the pooled analyses from five short-term, 
Table 3 Main adverse drug reactions reported in published clinical trials

\begin{tabular}{|c|c|c|c|c|}
\hline & \multicolumn{4}{|c|}{ Short term phase II trial (6 weeks) } \\
\hline & $\begin{array}{l}\text { Lurasidone } 80 \mathrm{mg} / \text { day } \\
(\mathrm{n}=90)\end{array}$ & \multicolumn{3}{|l|}{$\begin{array}{l}\text { Placebo } \\
(n=90)\end{array}$} \\
\hline EPS (\%) & NA & NA & & \\
\hline Akathisia (\%) & 8.9 & 3.3 & & \\
\hline \multicolumn{5}{|l|}{ Mean changes from baseline } \\
\hline QTc prolongation \pm SD (msec) & $-1.2 \pm 17.3$ & $+0.9 \pm 16.7$ & & \\
\hline Weight gain $(\mathrm{kg})^{*}$ & +0.9 & +0.5 & & \\
\hline Total cholesterol (mg/dL) & $-10.1 \pm N A$ & $-7.1 \pm N A$ & & \\
\hline Triglycerides (mg/dL) & -24.4 & $-31.7 \pm N A$ & & \\
\hline Glucose $(\mathrm{mg} / \mathrm{dL})$ & $+2.9 \pm N A$ & $+3.4 \pm N A$ & & \\
\hline \multirow[t]{3}{*}{ Prolactin $(\mathrm{ng} / \mathrm{mL})^{*}$} & +2.4 & -0.3 & & \\
\hline & \multicolumn{4}{|c|}{ Short-term phase III efficacy and safety trials (6 weeks) ${ }^{45}$} \\
\hline & $\begin{array}{l}\text { Lurasidone } 40 \mathrm{mg} / \mathrm{day} \\
(\mathrm{n}=\mathrm{I} / 9)\end{array}$ & $\begin{array}{l}\text { Lurasidone } 120 \mathrm{mg} / \text { day } \\
(\mathrm{n}=\mathrm{I} \mid \mathrm{8})\end{array}$ & $\begin{array}{l}\text { Olanzapine } 15 \mathrm{mg} / \mathrm{day} \\
(\mathrm{n}=122)\end{array}$ & $\begin{array}{l}\text { Placebo } \\
(n=I \mid 4)\end{array}$ \\
\hline Parkinsonism (\%) & 9.2 & 11.0 & 4.9 & 1.7 \\
\hline Tremor (\%) & 1.7 & 7.6 & 5.7 & 4.3 \\
\hline Dystonia (\%) & 3.4 & 7.6 & 0.8 & 0.9 \\
\hline Akathisia (\%) & 11.8 & 22.9 & 7.4 & 0.9 \\
\hline \multicolumn{5}{|l|}{ Mean changes from baseline } \\
\hline QTc prolongation \pm SD (msec) & $+5.1 \pm N A$ & $+4.5 \pm \mathrm{NA}$ & $+4.4 \pm \mathrm{NA}$ & $+3.8 \pm N A$ \\
\hline Weight gain \pm SD (kg) & $+1.0 \pm 2.9$ & $+1.0 \pm 2.2$ & $+4.1 \pm 4.3$ & $+0.6 \pm 2.7$ \\
\hline Total cholesterol $\pm \mathrm{SD}(\mathrm{mg} / \mathrm{dL})$ & $-8.6 \pm 29.8$ & $-7.3 \pm 25.3$ & $+9.6 \pm 31.2$ & $-6.8 \pm 28.7$ \\
\hline Triglycerides $\pm \mathrm{SD}$ (mg/dL) & $-8.3 \pm 76.2$ & $-5.0 \pm 85.5$ & $50.0 \pm 115.0$ & $0.1 \pm 64.8$ \\
\hline Glucose \pm SD (mg/dL) & $0.0 \pm 19.2$ & $+0.5 \pm 20.9$ & $+10.3 \pm 34.8$ & $+0.4 \pm 24.6$ \\
\hline \multirow[t]{3}{*}{ Prolactin $\pm S D(n g / L)$} & $+2.1 \pm 13.9$ & $+10.9 \pm 28.1$ & $+5.0 \pm 12.2$ & $-2.5 \pm 16.9$ \\
\hline & \multicolumn{4}{|c|}{ Short-term phase III efficacy and safety trials ( 3 weeks) ${ }^{43}$} \\
\hline & $\begin{array}{l}\text { Lurasidone } 120 \mathrm{mg} / \text { day } \\
(\mathrm{n}=\mid 50)\end{array}$ & $\begin{array}{l}\text { Ziprasidone } 160 \mathrm{mg} / \mathrm{day} \\
(\mathrm{n}=15 \mathrm{I})\end{array}$ & & \\
\hline EPS (\%) & 3.3 & 1.3 & & \\
\hline Akathisia (\%) & 3.3 & 6.6 & & \\
\hline \multicolumn{5}{|l|}{ Mean changes from baseline } \\
\hline QTc prolongation \pm SD (msec) & $+0.3 \pm 19.4$ & $+3.3 \pm 18.1$ & & \\
\hline Weight gain \pm SD $(\mathrm{kg})$ & $-0.27 \pm 1.7$ & $-0.4 I \pm 3.2$ & & \\
\hline Total cholesterol \pm SD (mg/dL) & $-6.4 \pm 24.0$ & $-4.4 \pm 30.4$ & & \\
\hline Triglycerides \pm SD (mg/dL) & $-2.6 \pm 86.6$ & $+22.4 \pm 258.8$ & & \\
\hline Glucose \pm SD (mg/dL) & $+4.7 \pm 20.8$ & $+4.8 \pm 25.0$ & & \\
\hline Prolactin \pm SD $(\mathrm{ng} / \mathrm{mL})^{*}$ & +3.0 & +2.0 & & \\
\hline
\end{tabular}

Note: *Only median changes were available.

Abbreviations: EPS, extrapyramidal symptoms; NA, not available.

placebo-controlled trials, mean increases in fasting glucose were $1.4 \mathrm{mg} / \mathrm{dL}$ in the lurasidone group and $0.6 \mathrm{mg} / \mathrm{dL}$ in the placebo group, but these changes were not statistically different. Short-term placebo-controlled trials and uncontrolled long-term trials found no dose-response relationship in the lurasidone group for mean changes in glucose levels. ${ }^{54}$ In clinical trials with an active comparator, changes in glucose were similar for lurasidone and ziprasidone $(+4.7$ and $+4.8 \mathrm{mg} / \mathrm{dL}$, respectively); glucose was also unchanged in lurasidone and placebo treated patients $(+1.0 \mathrm{mg} / \mathrm{dL})$ but higher in olanzapine and haloperidol-treated patients $\left(+4.0 \mathrm{mg} / \mathrm{dL}\right.$ and $+2.0 \mathrm{mg} / \mathrm{dL}$, respectively). ${ }^{43} \mathrm{In}$ a long-term trial in comparison with risperidone, lurasidone lowered glucose by $0.5 \mathrm{mg} / \mathrm{dL}$ from baseline, while risperidone raised it by $3.0 \mathrm{mg} / \mathrm{dL}^{.0}$

No increases were reported in total cholesterol, low-density lipoprotein cholesterol, or triglycerides in short-term trials comparing lurasidone with placebo. ${ }^{52,53}$ Mean changes in total cholesterol and triglycerides in uncontrolled long-term studies were -4.2 and $-13.6 \mathrm{mg} / \mathrm{dL}$, respectively, at week $24,-1.9$ and $-3.5 \mathrm{mg} / \mathrm{dL}$, respectively, at week 36 , and -3.6 and $-6.5 \mathrm{mg} / \mathrm{dL}$, respectively, at week $52 .{ }^{54}$ In short-term controlled studies, lurasidone was associated with a reduction in triglycerides $(-2.6 \mathrm{mg} / \mathrm{dl})$ while ziprasidone was associated with an increase 
(+22.4 mg/dL), but no difference was reported for mean change in total cholesterol ( -6.4 and $-4.4 \mathrm{mg} / \mathrm{dL}$, respectively). ${ }^{43} \mathrm{In}$ controlled clinical trials with placebo and olanzapine, mean changes in total cholesterol were comparable for lurasidone $40 \mathrm{mg} /$ day, $120 \mathrm{mg} /$ day, and placebo group (-8.6, -7.3, and $-6.8 \mathrm{mg} / \mathrm{dL}$, respectively), while there was a significant increase in the olanzapine group $(+9.6 \mathrm{mg} / \mathrm{dL})$. Mean triglyceride levels decreased with lurasidone $(-8.3$ and $-5.0 \mathrm{mg} / \mathrm{dL}$ for lurasidone 40 and $120 \mathrm{mg}$ /day, respectively), increased for olanzapine treated patients $(+50.0 \mathrm{mg} / \mathrm{dL})$ and remained unchanged in the placebo group $(+0.1 \mathrm{mg} / \mathrm{dL}) .{ }^{45} \mathrm{In}$ the pooled analyses from five short-term, placebo-controlled trials, mean changes in total cholesterol and triglycerides were similar for lurasidone (-8.0 and $-5.0 \mathrm{mg} / \mathrm{dL}$, respectively), haloperidol (-8.0 and $-3.0 \mathrm{mg} / \mathrm{dL}$, respectively), and placebo ( -10.0 and $-7.0 \mathrm{mg} / \mathrm{dL}$, respectively) ${ }^{52,53}$ In a 6-week randomized clinical trial comparing lurasidone with placebo and quetiapine, lurasidone reduced triglyceride levels to a similar level to placebo $(-9.0 \mathrm{mg} / \mathrm{dL}$ for placebo, and -2.0 and $-9.0 \mathrm{mg} / \mathrm{dL}$ for lurasidone 80 and $160 \mathrm{mg}$ /day, respectively), while quetiapine raised triglyceride levels (+8.0 mg/dL). ${ }^{53,54}$ In a long-term controlled trial with risperidone, the median reduction from baseline for lipid variables was similar in lurasidone and risperidone groups. ${ }^{50}$

\section{Weight gain}

The overall effects of lurasidone on body weight appear to be minimal. Short-term clinical trials showed a mean weight gain of $0.75 \mathrm{~kg}$ in the lurasidone group and $0.26 \mathrm{~kg}$ in the placebo group. The proportion of patients with weight gain, defined as an increase of more than $7 \%$ in body weight, was similar for lurasidone, haloperidol, and placebo $(5.6 \%, 4.2 \%$, and $4 \%$ respectively).$^{52,53}$ The proportion of patients with clinically significant weight gain was similar for lurasidone $(7.6 \%$ for $40 \mathrm{mg}$ and $7.0 \%$ for $120 \mathrm{mg}$ ) and placebo (4.2\%), but higher (34.4\%) in the olanzapine group. The mean increase in body weight was higher for olanzapine $(4.1 \mathrm{~kg})$ than with placebo $(0.6 \mathrm{~kg})$ and lurasidone $(1.0 \mathrm{~kg})$. The effect did not appear to be dose-related ( $1.0 \mathrm{~kg}$ for both lurasidone $40 \mathrm{mg}$ and $120 \mathrm{mg}$ ). ${ }^{45}$ Another study found that weight gain was similar with lurasidone and placebo $(0.6 \mathrm{~kg}$ and $0.1 \mathrm{~kg})$, but higher for quetiapine-treated patients $(2.1 \mathrm{~kg}) .{ }^{54}$ Mean changes in weight were also similar for lurasidone and ziprasidone $\left(-0.29 \mathrm{~kg}\right.$ and $-0.16 \mathrm{~kg}$, respectively), ${ }^{43}$ a finding which is of interest as ziprasidone is an antipsychotic associated with a low risk of weight gain, but long-term data are limited. Effects on body weight were also minimal in a long-term randomized clinical trial where the mean change in weight was $-0.9 \mathrm{~kg}$ in the lurasidone group and $+2.6 \mathrm{~kg}$ in the risperidone group after 12 months. ${ }^{50}$

\section{Hyperprolactinemia}

Lurasidone can raise prolactin levels, with a dose-dependent relationship in short-term clinical trials. Hyperprolactinemia was slightly greater in female patients. In the pooled analysis of short-term placebo-controlled trials, the mean change in prolactin levels from baseline was significantly different from placebo: $+1.1 \mathrm{ng} / \mathrm{mL}$ for lurasidone-treated patients $(0.3 \mathrm{ng} / \mathrm{mL}$ for $40 \mathrm{mg}$ and $3.4 \mathrm{ng} / \mathrm{ml}$ for $120 \mathrm{mg})$ and $-0.6 \mathrm{ng} / \mathrm{mL}$ for placebo-treated patients. ${ }^{52}$ Mean changes in prolactin levels were greater in patients treated with haloperidol ( $+8.5 \mathrm{ng} / \mathrm{mL})$, than with olanzapine, lurasidone, and placebo $(+3.7 \mathrm{ng} / \mathrm{mL},+1.1 \mathrm{ng} / \mathrm{mL}$, and $-0.5 \mathrm{ng} / \mathrm{mL}$, respectively). ${ }^{55}$ The increase in prolactin level for lurasidone $120 \mathrm{mg} /$ day $(+10.9 \mathrm{ng} / \mathrm{mL})$ was significantly greater than with olanzapine $(+5.0 \mathrm{ng} / \mathrm{ml})$ or placebo $(-2.5 \mathrm{ng} / \mathrm{ml}) .{ }^{45}$ Compared to ziprasidone, the median increase in prolactin was significantly greater in the lurasidone group $(2.0 \mathrm{ng} / \mathrm{mL}$ and $3.0 \mathrm{ng} / \mathrm{mL}$, respectively). ${ }^{43}$ No symptoms were reported in either study, and no patients discontinued study medication because of high prolactin levels. ${ }^{43,45}$ Compared to risperidone, median increases from baseline at 12 months were $0.10 \mathrm{ng} / \mathrm{mL}$ for lurasidone and $9.10 \mathrm{ng} / \mathrm{mL}$ for risperidone. ${ }^{50}$ Uncontrolled long-term trials reported no increase in prolactin concentrations: lurasidone was associated with a change in prolactin of $-1.9 \mathrm{ng} / \mathrm{mL}$ at week $24,-5.4 \mathrm{ng} / \mathrm{mL}$ at week 36 , and $-3.3 \mathrm{ng} / \mathrm{mL}$ at week $52 .{ }^{42}$

\section{Dosing schedules}

Lurasidone hydrochloride has been shown to be effective in a dose range of 20 to $120 \mathrm{mg}$ /day, although the lowest dose was less effective in terms of improvement in schizophrenia symptoms. Six-week controlled trials, however, have found no suggestion of added benefit with $120 \mathrm{mg} /$ day. There was a dose-related increase in certain adverse reactions (in particular somnolence and EPS), with greater discontinuation rates due to adverse events at the higher doses. Therefore, the maximum recommended dose is $80 \mathrm{mg} /$ day. ${ }^{42}$

In clinical practice, lurasidone is given orally once daily, with the recommended starting dose of $40 \mathrm{mg}$ /day, taken with food (at least 350 calories), with no initial dose titration required. Dose adjustments are not required on the basis of age, sex, or race, but for patients with moderate to severe renal or hepatic impairment the dose of lurasidone hydrochloride should not exceed $40 \mathrm{mg} /$ day. The relatively long $\mathrm{t}_{1 / 2}$ in comparison to many other atypical antipsychotics ${ }^{30,31}$ allows once-daily administration. Theoretically, this may result in low fluctuations in steady-state concentrations of the parent drug and its active metabolites in plasma and target 
sites, although it would be useful to characterize the rate of elimination and extent of accumulation of the parent drug and its active metabolites in the various patient populations.

The dose should also not exceed $40 \mathrm{mg}$ /day when lurasidone hydrochloride is co-administered with moderate CYP3A4 inhibitors such as diltiazem. Co-administration with potent inhibitors of hepatic and intestinal CYP3A4 such as ketoconazole and grapefruit juice or CYP3A4 inducers such as rifampin and high-hyperforin extracts of Hypericum perforatum is contraindicated. ${ }^{42}$

\section{Place of lurasidone in therapy}

Lurasidone is similar to many older antipsychotics in its affinity for $\mathrm{D}_{2}$ and $5-\mathrm{HT}_{2 \mathrm{~A}}$ and, as with atypical agents, it exerts antipsychotic activity with a limited risk of EPS. On the basis of its potent antagonism of 5- $\mathrm{HT}_{7}$ and high affinity for other receptors implicated in the enhancement of cognitive function, particularly $5-\mathrm{HT}_{1 \mathrm{~A}}$ at which is acts as a partial agonist, lurasidone was hypothesized to have favorable effects on cognition, memory, and mood, although this hypothesis is not currently supported by clinical evidence. The drug is also expected to possess anxiolytic- or antidepressant-like activity in clinical use because of its higher affinities for $5-\mathrm{HT}_{7}$ and $5-\mathrm{HT}_{1 \mathrm{~A}}$ receptors. Moreover, it shows little binding affinity for $\alpha 1$-adrenergic receptors, suggesting that it should have a low risk for orthostatic hypotension and sedation.

Affinity at the histamine $H_{1}$ and muscarinic $M_{1}$ receptors was also very low, which supports a favorable side-effect profile for this drug. Clinical trials to date indicate that the most common adverse events associated with lurasidone are mild akathisia, sedation, and Parkinsonism. The rates of these events are low and dose-related. Early data also showed minimal risks for weight gain and metabolic abnormalities, similar to some other new antipsychotics such as aripiprazole, iloperidone, and ziprasidone. Additionally, there are only minimal increases in prolactin levels with no significant increases in QTc, which is in contrast to iloperidone and ziprasidone. This may give lurasidone an advantage over some atypical antipsychotics, but further trials with a broader population of patients would be useful to explore these areas.

Although lurasidone was effective and generally well tolerated in several short-term placebo controlled trials, these enrolled only small numbers of highly selected patients, and studies that compared lurasidone with an active comparator were not designed to directly test the differences among antipsychotics. These weaknesses limit the general extension of the results to patients with other psychological or clinical comorbidities, those with comorbid drug use and/ or dependence, patients who are resistant to treatment with other antipsychotics, and adolescents or elderly patients. Moreover, data are limited on lurasidone's effectiveness in the maintenance treatment of schizophrenia. The only data on the drug's long-term efficacy come from the extension phase of some short-term studies.

Although none of the patients treated with lurasidone experienced significant QTc change, electrocardiographic changes for haloperidol and ziprasidone, which are included in the list of drugs associated with the risk of torsades de pointes, are lower than expected. ${ }^{56-58}$ However, to date lurasidone has been tested in a small sample of patients and the risk of torsades de pointes in the general populations remains unknown. Additional studies on larger samples of patients are therefore required. Lurasidone also appears to have a low potential for causing weight gain and adverse metabolic effects, but longer-term trials are needed to assess the risk of new-onset diabetes, which is of particular concern with second-generation antipsychotics. ${ }^{59,60}$ Long-term treatment with antipsychotic drugs, especially at high dosages, is also associated with the risk of tardive dyskinesia, and this potential adverse reaction may be underestimated because of the limited information available at this time from longterm clinical trials.

When compared with other recent second-generation antipsychotics that also have a low propensity for causing the adverse effects of older antipsychotics, lurasidone has further potential advantages including once-daily administration (unlike the twice-daily administration required for asenapine, iloperidone, and ziprasidone) and the fact that dosing titration is not necessary (in contrast to asenapine, iloperidone, sertindole, and ziprasidone). ${ }^{25,61-63}$ Lurasidone's advantage of once-daily dosing (which is shared by the long $\mathrm{t}_{1 / 2}$ aripiprazole and sertindole, among the newer antipsychotics), ${ }^{30,62}$ should also help improve patient compliance.

Beneficial features of lurasidone include the lack of clinically significant age-, sex-, or race-related effects. ${ }^{28,30,41}$ These results must, however, be extended to its active metabolites, whose pharmacological and pharmacokinetic profiles and potential contributions to the overall outcome are still largely unknown.

Although clinicians will need to consider lurasidone's favorable side-effect profile when making a therapeutic decision, this new antipsychotic has some disadvantages. Whereas food does not significantly affect the absorption of most antipsychotics, lurasidone must be administered carefully in 
relation to meals in order to optimize bioavailability (another exception is ziprasidone, although this has a higher caloric threshold than lurasidone). ${ }^{28,63}$ Dose adjustment is recommended in moderate and severe renal or hepatic impairment, in contrast to the dose reductions recommended for paliperidone in renal impairment and for iloperidone and sertindole in hepatic impairment, while no adjustments are needed for aripiprazole and ziprasidone..$^{25,30,62}$ Being primarily biotransformed by CYP3A4, co-administration with strong inducers and inhibitors of CYP3A4 is contraindicated, a disadvantage shared by most of the newer lipophilic antipsychotics, although carbamazepine and ketoconazole have less effect on the clearance of antipsychotics that have significant alternative pathways (for example, ziprasidone is partly metabolized by aldehyde oxidase, while paliperidone's clearance is largely due to urinary excretion of the drug itself). Unlike aripiprazole, iloperidone, sertindole, and many older antipsychotics, however, lurasidone does not present any of the polymorphic metabolism characteristics mirroring the CYP2D6 phenotype, ${ }^{25,30,62}$ and can therefore be administered in combination with CYP2D6 inhibitors, regardless of patient's genetic status. ${ }^{41,42}$

Lastly, the clinical advantages of the new antipsychotic agents have not been well evaluated in direct superiority comparative studies. The lack of well-designed long-term comparative studies and the unnecessary and excessive use of placebo in the few short-term studies that are available add to the difficulty of establishing the place of lurasidone and the other new agents in therapy, and providing clinicians with clear guidance on the choice of the best treatment for each patient. Well-designed and appropriately powered clinical studies are now needed to assess the therapeutic role of lurasidone in schizophrenia.

\section{Disclosure}

The authors report no conflict of interest in this work.

\section{References}

1. Saha S, Chant D, Welham J, McGrath J. A systematic review of the prevalence of schizophrenia. PLoS Med. 2005;2(5):e141.

2. Stahl SM. Symptoms and circuits, part 3: schizophrenia. J Clin Psychiatry. 2004;65(1):8-9.

3. Seeman MV. Symptoms of schizophrenia: normal adaptations to inability. Med Hypotheses. 2007;69(2):253-257.

4. Wu EQ, Birnbaum HG, Shi L, et al. The economic burden of schizophrenia in the United States in 2002. J Clin Psychiatry. 2005;66(9):1122-1129.

5. Salize HJ, McCabe R, Bullenkamp J, et al. Cost of treatment of schizophrenia in six European countries. Schizophr Res. 2009;111(1-3):70-77.

6. Rössler W, Salize HJ, van Os J, Riecher-Rössler A. Size of burden of schizophrenia and psychotic disorders. Eur Neuropsychopharmacol. 2005;15(4):399-409.
7. Seeman P, Lee T, Chau-Wong M, Wong K. Antipsychotic drug doses and neuroleptic/dopamine receptors. Nature. 1976;261(5562):717-719.

8. American Psychiatric Association. Practice Guidelines for the Treatment of Patients with Schizophrenia. 2nd ed. Arlington, VA: American Psychiatric Association; 2004.

9. Bishara D, Taylor D. Upcoming agents for the treatment of schizophrenia:mechanism of action, efficacy and tolerability. Drugs. 2008;68(16):2269-2292.

10. Gaebel W, Falkai P, Weinmann S, Wobrock T. Treatment Guidelines for Schizophrenia [Behandlungsleitlinie Schizophrenie]. Stuttgart, Germany: Steinkopf; 2006. German.

11. Miyamoto S, Duncan GE, Marx CE, Lieberman JA. Treatments for schizophrenia: a critical review of pharmacology and mechanisms of action of antipsychotic drugs. Mol Psychiatry. 2005;10(1): 79-104.

12. Meltzer HY, Matsubara S, Lee JC. The ratios of serotonin2 and dopamine2 affinities differentiate atypical and typical antipsychotic drugs. Psychopharmacol Bull. 1989;25(3):390-392.

13. Meltzer HY. The role of serotonin in antipsychotic drug action. Neuropsychopharmacology. 1999;21(Suppl 2):106S-115S.

14. Luft B, Taylor D. A review of atypical antipsychotic drugs versus conventional medication in schizophrenia. Expert Opin Pharmacother. 2006;7(13):1739-1748.

15. Haddad PM, Sharma SG. Adverse effects of atypical antipsychotics: differential risk and clinical implications. CNS Drugs. 2007;21(11):911-936.

16. Kroeze WK, Hufeisen SJ, Popadak BA, et al. H1-histamine receptor affinity predicts short-term weight gain for typical and atypical antipsychotic drugs. Neuropsychopharmacology. 2003;28(3):519-526.

17. Haddad P. Weight change with atypical antipsychotics in the treatment of schizophrenia. J Psychopharmacol. 2005;19(Suppl 6):16-27.

18. Dorado P, Berecz R, Peñas-Lledó EM, Llerena A. Antipsychotic drugs and QTc prolongation: the potential role of CYP2D6 genetic polymorphism. Expert Opin Drug Metab Toxicol. 2007;3(1):9-19.

19. Lieberman JA, Stroup TS, McEvoy JP, et al. Effectiveness of antipsychotic drugs in patients with chronic schizophrenia. $N$ Engl J Med. 2005;353(12):1209-1223.

20. Jones PB, Barnes TR, Davies L, et al. Randomized controlled trial of the effect on quality of life of second- vs. first-generation antipsychotic drugs in schizophrenia: Cost Utility of the Latest Antipsychotic Drugs in Schizophrenia Study (CUtLASS 1). Arch Gen Psychiatry. 2006;63(10):1079-1087.

21. Buchanan RW, Kreyenbuhl J, Kelly DL, et al. The 2009 schizophrenia PORT psychopharmacological treatment recommendations and summary statements. Schizophr Bull. 2010;36(1):71-93.

22. Naber D, Lambert M. The CATIE and CUtLASS studies in schizophrenia: results and implications for clinicians. CNS Drugs. 2009;23(8):649-659.

23. Foussias G, Remington G. Antipsychotics and schizophrenia: from efficacy and effectiveness to clinical decision-making. Can J Psychiatry. 2010;55(3):117-125.

24. Citrome L. Asenapine for schizophrenia and bipolar disorder: a review of the efficacy and safety profile for this newly approved sublingually absorbed second-generation antipsychotic. Int J Clin Pract. 2009;63(12):1762-1784.

25. Caccia S, Pasina L, Nobili A. New atypical antipsychotics for schizophrenia: iloperidone. Drug Des Devel Ther. 2010;4:33-48.

26. United States Food and Drug Administration. FDA Approves Latuda to Treat Schizophrenia in Adults. Available from: http://www.fda. gov/NewsEvents/Newsroom/PressAnnouncements/ucm231512.htm. Accessed March 20, 2012.

27. Meyer JM, Loebel Ad, Schweizer E. Lurasidone: a new drug in development for schizophrenia. Expert Opin Investig Drugs. 2009;18(11):1715-1726.

28. Citrome L. Lurasidone for schizophrenia: a review of the efficacy and safety profile for this newly approved second-generation antipsychotic. Int J Clin Pract. 2011;65(2):189-210. 
29. Citrome L. Lurasidone for schizophrenia: a brief review of a new second-generation antipsychotic. Clin Schizophr Relat Psychoses. 2011;4(4):251-257.

30. Caccia S. Pharmacokinetics and metabolism update for some recent antipsychotics. Expert Opin Drug Metab Toxicol. 2011;7(7):829-846.

31. Caccia S. Biotransformation of post-clozapine antipsychotics: pharmacological implications. Clin Pharmacokinet. 2000;38(5):393-414.

32. Ishibashi T, Horisawa T, Tokuda K, et al. Pharmacological profile of lurasidone, a novel antipsychotic agent with potent 5-hydroxytryptamine 7 (5-HT7) and 5-HT1A receptor activity. J Pharmacol Exp Ther. 2010;334(1):171-181.

33. Horiguchi M, Huang M, Meltzer HY. The role of 5-hydroxytryptamine 7 receptors in the phencyclidine-induced novel object recognition deficit in rats. J Pharmacol Exp Ther. 2011;338(2):605-614.

34. Meltzer HY, Massey BW. The role of serotonin receptors in the action of atypical antipsychotic drugs. Curr Opin Pharmacol. 2011;11(1): 59-67.

35. Meneses A. Effects of the 5-HT receptor antagonists SB-269970 and DR 4004 in autoshaping Pavlovian/instrumental learning task. Behav Brain Res. 2004;155(2):275-282.

36. Guscott M, Bristow LJ, Hadingham K, et al. Genetic knockout and pharmacological blockade studies of the $5-\mathrm{HT}_{7}$ receptor suggest therapeutic potential in depression. Neuropharmacology. 2005;48(4): 492-502.

37. Terry AV Jr, Buccafusco JJ, Wilson C. Cognitive dysfunction in neuropsychiatric disorders: selected serotonin receptor subtypes as therapeutic targets. Behav Brain Res. 2008;195(1):30-38.

38. Newman-Tancredi A, Kleven MS. Comparative pharmacology of antipsychotics possessing combined dopamine D2 and serotonin 5-HT1A receptor properties. Psychopharmacology (Berl). 2011;216(4):451-473.

39. Ohno Y. Therapeutic role of 5-HT1 A receptors in the treatment of schizophrenia and Parkinson's disease. CNS Neurosci Ther. 2011;17(1):58-65.

40. Swainston Harrison T, Perry CM. Aripiprazole: a review of its use in schizophrenia and schizoaffective disorder. Drugs. 2004;64(15):1715-1736.

41. Food and Drug Administration. Drug Approval Package. Latuda (lurasidone hydrochloride) Tablets. Sunovion Pharmaceuticals, Inc. Clinical Review; Pharmacology Review(s); Clinical Pharmacology Biopharmaceutics Review(s). Available from: http://www.accessdata. fda.gov/drugsatfda_docs/nda/2010/200603Orig1s000PharmR.pdf. Accessed March 21, 2012.

42. Sunovion Pharmaceutical Inc. Latuda (lurasidone $\mathrm{HCl}$ ) [Prescribing Information]. Sunovion Pharmaceutical Inc. Available from: http:// www.latuda.com/LatudaPrescribingInformation.pdf. Accessed March 21, 2012.

43. Potkin, SG, Ogasa M, Cucchiaro J, Loebel A. Double-blind comparison of the safety and efficacy of lurasidone and ziprasidone in clinically stable outpatients with schizophrenia or schizoaffective disorder. Schizophr Res. 2011;132(2-3):101-107.

44. Nakamura M, Ogasa M, Guarino J, et al. Lurasidone in the treatment of acute schizophrenia: a double-blind, placebo-controlled trial. J Clin Psychiatry. 2009;70(6):829-836.

45. Meltzer HY, Cucchiaro J, Silva R, et al. Lurasidone in the treatment of schizophrenia: a randomized, double-blind, placebo- and olanzapinecontrolled study. Am J Psychiatry. 2011;168(9):957-967.

46. Meltzer H, Cucchiaro J, Silva R, et al. Lurasidone in the treatment of acute schizophrenia: results of the double-blind, placebo-controlled PEARL 2 trial [abstract]. Presented at: American College of Neuropsychopharmacology; December 6-10, 2009; Hollywood, Fla. Abstract 76.

Neuropsychiatric Disease and Treatment

\section{Publish your work in this journal}

Neuropsychiatric Disease and Treatment is an international, peerreviewed journal of clinical therapeutics and pharmacology focusing on concise rapid reporting of clinical or pre-clinical studies on a range of neuropsychiatric and neurological disorders. This journal is indexed on PubMed Central, the 'PsycINFO' database and CAS.
47. Cucchiaro J, Potkin S, Ogasa M, Loebel A. A double-blind comparison of the safety and efficacy of lurasidone and ziprasidone in clinically stable outpatients with schizophrenia or schizoaffective disorder. Schizophr Bull. 2009;35 Suppl 1:342-343.

48. Harvey PD, Murasaki M, Cucchiaro J, Ogasa M, Loebel A. A three arm dose finding study of lurasidone: Efficacy and tolerability data. Schizophr Res. 2010;117:374-375-Abstract.

49. Loebel A, Cucchiaro J, Silva R, Ogasa M, Severs J, Marder SR. Efficacy of lurasidone in schizophrenia: Results of a pooled analysis based on a 5-factor model of schizophrenia. Schizophr Res. 2010;117:267-Abstract.

50. Dainippon. Completion Of Long-Term Phase 3 Safety Trial for Latuda ${ }^{\circledR}$ (lurasidone $\mathrm{HCl}$ ). Available from: http://www.ds-pharma.com/ news/2011/20110125.html. Accessed March 21, 2012.

51. Ogasa M, Loebel A, Cucchiaro J, et al. Effect of lurasidone on depressive symptoms in patients with schizophrenia. Schizophr Bull. 2009;35: 344-345-Abstract.

52. Cucchiaro J, Pikalov A, Ogasa M. Safety of lurasidone: Pooled analysis of five placebo-controlled trials in patients with schizophrenia. Int $J$ Neuropsychopharmacol. 2010;13 Suppl 1:217-Abstract.

53. Samalin L, Garnier M, Llorca PM. Clinical potential of lurasidone in the management of schizophrenia. Ther Clin Risk Manag. 2011;7: 239-250.

54. Latuda Significantly Improves Symptoms of Schizophrenia in Fifth Positive Placebo-Controlled Study. Available from: http://www.ds-pharma. com/news/pdf/ene20101209.pdf. Accessed March 21, 2012.

55. Ehret MJ, Sopko MA. Focus on lurasidone: a new atypical antipsychotic for the treatment of schizophrenia. Formulary 2010;45:313-317.

56. United States Food and Drug Administration. Information for Healthcare Professionals: Haloperidol (marketed as Haldol, Haldol Decanoate and Haldol Lactate). FDA alert. Available from: http://www.fda.gov/Drugs/ DrugSafety/PostmarketDrugSafetyInformationforPatientsandProviders/ DrugSafetyInformationforHeathcareProfessionals/ucm085203.htm. Accessed March 21, 2012.

57. United States Food and Drug Administration. Safety Information and Adverse Event Reporting Program. Geodon (ziprasidone $\mathrm{HCl}$ ) Dear Healthcare Professional Letter. Available from: http://www.fda.gov/ Safety/MedWatch/SafetyInformation/SafetyAlertsforHumanMedical Products/ucm170899.htm. Accessed March 21, 2012.

58. Heinrich TW, Biblo LA, Schneider J. Torsades de pointes associated with ziprasidone. Psychosomatics. 2006;47(3):264-268.

59. Newcomer JW. Metabolic considerations in the use of antipsychotic medications: a review of recent evidence. J Clin Psychiatry. 2007; 68 Suppl 1:20-27.

60. Buchholz S, Morrow AF, Coleman PL. Atypical antipsychoticinduced diabetes mellitus: an update on epidemiology and postulated mechanisms. Intern Med J. 2008;38(7):602-606.

61. Chwieduk CM, Scott LJ. Asenapine: a review of its use in the management of mania in adults with bipolar I disorder. CNS Drugs. 2011;25(3):251-267.

62. Murdoch D, Keating GM. Sertindole: a review of its use in schizophrenia. CNS Drugs. 2006;20(3):233-255.

63. Gunasekara NS, Spencer CM, Keating GM. Ziprasidone: a review of its use in schizophrenia and schizoaffective disorder. Drug. 2002;62(8):1217-1251.

The manuscript management system is completely online and includes a very quick and fair peer-review system, which is all easy to use. Visit http://www.dovepress.com/testimonials.php to read real quotes from published authors. 